\title{
EVALUATION OF MINI-IMPLANT ANCHORAGE SYSTEM FOR EN-MASSE RETRACTION OF MAXILLARY ANTERIOR TEETH VERSUS CONVENTIONAL METHOD
}

\author{
Shaimaa M. El-Marhoumy "; Mahmoud E. El-Shenawy **; \\ Medhat M. El-Sakhawy ** and Eman M. El-Shorbagy **
}

\begin{abstract}
Objectives: The purpose of this study was to compare the skeletodental and soft tissue changes and the duration needed for closure of extraction space after en-masse retraction of maxillary anterior teeth using mini-implant anchorage system in the treatment of maxillary dentoalveolar protrusion cases compared with two step retraction with conventional method of anchorage reinforcement.

Materials and Methods: The study sample consisted of twenty adult orthodontic patients (3 males and 17 females) with maxillary dentoalveolar protrusion and required first premolar extraction and maximum anchorage. They were randomly divided into two treatment groups (10 subjects in each group). Group 1, anterior space closure with en-masse retraction aided by miniimplant anchorage system, or group 2, anterior space closure with two-step retraction technique aided by conventional method of anchorage. Lateral cephalometric head films were taken just before retraction of maxillary anterior teeth and immediately after closure of the extraction space for the evaluation of the treatment changes. Statistical analyses of the data were performed at a significance level of $\mathrm{P}<0.05$.
\end{abstract}

Results: For the skeletal parameters, a statistically significant decrease in the facial vertical dimensions was seen in $\mathrm{G} 1$, but the variables in G2 showed no significant differences $(\mathrm{P}>0.05)$. Anchorage loss, in both the horizontal and vertical directions, was noted in G2, whereas G1 showed anchorage gain and intrusion of molars. Group 1 had greater anterior tooth retraction $(7.8 \mathrm{~mm}$ in 9.6 months) than did the conventional anchorage group (5.5 mm in 12.4 months). However, no significant differences in the mean retraction time were noted between the 2 groups. Upper incisors were intruded in $\mathrm{G} 1(2.3 \mathrm{~mm})$ and extruded $(1.1 \mathrm{~mm})$ in $\mathrm{G} 2$. The soft-tissue response was greater changes in G1 with significant differences were found in the nasolabial angle and amount of upper lip retraction between the groups $(\mathrm{P}<0.05)$.

Conclusion: Mini-implants provided absolute anchorage to allow greater skeletal, dental, and esthetic changes in patients requiring maximum anterior retraction, when compared with other conventional methods of anchorage reinforcement. However no differences in the mean retraction time were noted between the 2 groups.

KEYWORDS: En-masse retraction, mini-implants, maximum anchorage.

P.H.D., Orthodontic Department, Faculty of Dentistry, Tanta University, Egypt

** Professor of Orthodontic, Faculty of Dentistry, Tanta University, Egypt 


\section{INTRODUCTION}

Dentoalveolar protrusion is one of the chief complaints in adult orthodontic patients. So, a major orthodontic treatment goal in patients with maxillary protrusion is to reduce the protrusive lips and improve the facial esthetics ${ }^{[1-3]}$.

In correcting a maxillary dentoalveolar protrusion, extraction of the bilateral maxillary first premolars is a common approach to provide space for anterior retraction and to decrease facial convexity and lip procumbency. As for patients with maxillary dentoalveolar protrusion, the more extraction that space is used for the retraction of anterior teeth, the better the facial profile would be. Therefore, anchorage loss should be minimized wherever possible in these patients ${ }^{[4,5]}$.

Obtaining maximum or absolute anchorage has always been an arduous goal for the practicing orthodontist, often resulting in a condition, dreaded by most, called anchorage loss ${ }^{[6]}$. To address this problem, many appliances and techniques have been devised; Nance holding arch, transpalatal bars, extraoral traction, multiple teeth at the anchorage segment, intermaxillary elastics and distal tipback bend are some commonly used ones ${ }^{[7-10]}$. However, all these methods have a few inherent disadvantages complicated designs, need for exceptional patient cooperation, elaborate wire bending, and so on ${ }^{[6]}$.

Titanium mini-implants have gained enormous popularity in the orthodontic community and has been developed to satisfy a large set of requirements to be used as absolute sources of orthodontic anchorage such as, easy placement and removal, low cost, small size, availability to be implanted in many areas in the maxilla and the mandible that were previously unavailable, including between the roots of adjacent teeth without discernable damage to tooth roots. With the option of self-taping and self-drilling, capability of immediate loading and ability to simpilify orthodontic treatment by allowing more difficult tooth movements to be precisely controlled, such as intrusion, distalization and en-masse retraction of anterior teeth ${ }^{[11-18]}$.

The orthodontic literature lacks comparative clinical studies on the effects of mini-implant supported en-masse retraction with the twostep retraction techniques aided with traditional anchorage devices. The present study aimed to compare the skeletal, dental and soft tissue treatment effects and the duration of retraction between en-masse retraction of upper anterior teeth employing mini-implants and the two-step retraction approach employing conventional methods of anchorage reinforcement in patients with maxillary dentoalveolar protrusion.

\section{MATERIAL AND METHODS}

The sample of the present study comprised of 20 patients ( 3 males and 17 females) seeking orthodontic treatment in Orthodontic Department, Faculty of Dentistry, Tanta University. The patient's age ranged from 18 to 24 years at the start of the treatment with Class II division 1 malocclusion, orthodontic treatment plan required extraction of two maxillary first premolars and maximum anchorage permanent dentition, no medical or dental contraindications for orthodontic treatment, no previous orthodontic treatment and good oral hygiene.

The patients were randomly divided into two groups. In group 1,10 patients $(2$ males and 8 females) were treated by using mini-implants; in group 2, 10 patients (1 male and 9 females) were treated with conventional methods of anchorage reinforcement.

In group 1, an informed consent was obtained before implantation after explaining the treatment procedure in detail to all patients. Roth appliance (Straight- wire synthesis. Ormco. USA) was bonded to the upper teeth. After the initial leveling and alignment, 0.017 X 0.025-in stainless steel archwire with crimpable hooks placed distal to the lateral 
incisors was placed in the maxillary arch. To ensure that the wire was passive, it was left in place for at least four weeks before starting retraction.

Two miniscrews (AbsoAnchor orthodontic microimplant, Dentos, Korea), $1.3 \mathrm{~mm}$ in diameter and $8 \mathrm{~mm}$ in length, were implanted bilaterally between the maxillary second premolar and the first permanent molar using appropriate screwdriver (Fig.1). A force of 150-g was applied immediately on each side with nickel-titanium closed coil spring extending from the implant to the crimpable hook for en-masse retraction of the maxillary anterior teeth (Fig.2).

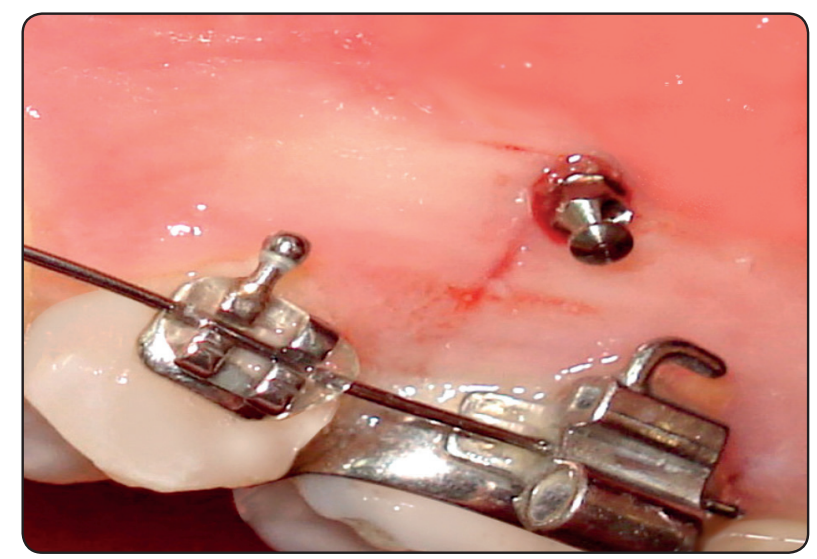

Fig (1) Mini-implant in place

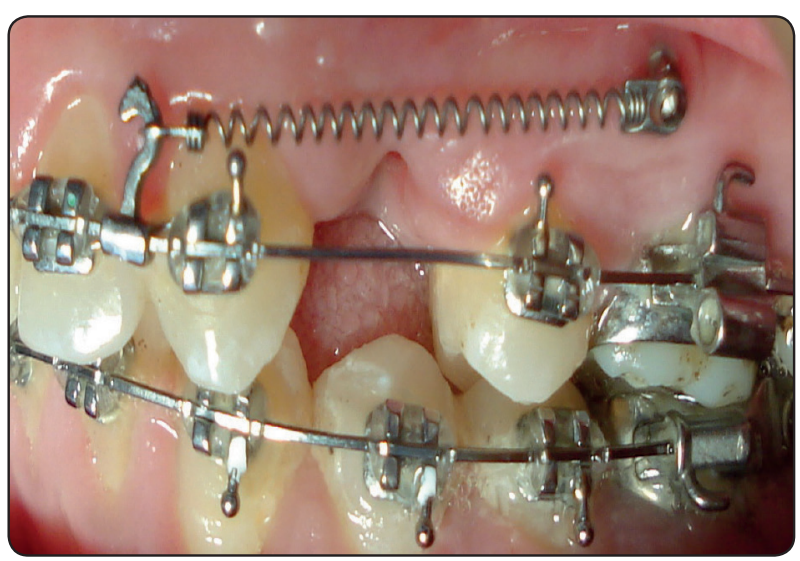

Fig. (2) Force application with nickel-titanium closed coil spring
The force was checked using the force gauge at the level of the hook to the coil spring. Measurements of the stability of the implant, soft-tissue health around the implant, and patient comfort were recorded at every clinical appointment (about every 30 days) during the study.

In group 2 , Roth brackets $(0.022 \times 0.028$ inch slot) were bonded to the upper teeth. According to individual case need, sequential aligning arch wires were used until 0.017 X 0.025 -in stainless steel archwire was placed in the maxillary arch. Conventional means of anchorage reinforcement were used such as; transpalatal arches, banding of the maxillary second molar, and multiple teeth at the anchorage segment (Fig.3). The anterior teeth were retracted sequentially retraction of maxillary canines first then the maxillary incisors.

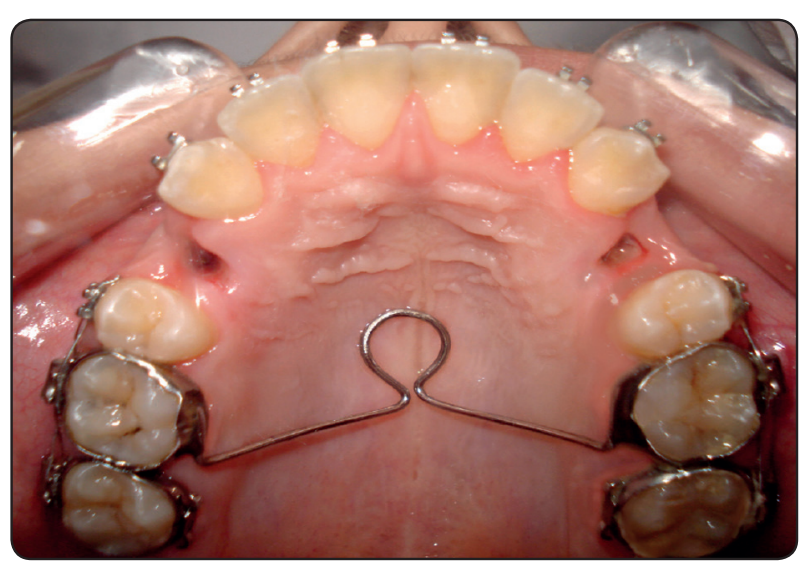

Fig. (3) Conventional means of anchorage reinforcement

Standardized lateral cephalometric radiographs were taken just before retraction of the maxillary anterior teeth (T1) and immediately after closure of the extraction space for the evaluation of the treatment changes (T2). Each cephalogram was traced and analyzed by the same operator and checked by the supervisors. The cephalometric measurements were categorized into skeletal measurements (SNA, SNB, ANB, SN-MP, UFH, LFH, PFH, TAFH, UFH LFH, PFH\TAFH, LFH TAFH), dental measurements (U1-SN, U1-L1, 
U1-Sv, U1-PP, U6-PP, U6-SV) and soft tissue measurements (G-Sn-Pog', nasolabial angle, NtSv, Ls-Sv, E-line-Ss, E-line-Ls). Horizontal and vertical positional changes of certain landmarks will be measured in relation to a Cartesian coordinate system. The Frankfort horizontal plane (constructed by subtracting $7^{\circ}$ from the sella-nasion line) served as $\mathrm{X}$-axis and a line perpendicular to it through sella served as Y-axis (Fig.4, 5, 6).

\section{Statistical analysis:}

The radiographs were remeasured after a period of 2 weeks, and the readings of the first estimation were compared to the second one. A tolerance limit of $0.5 \mathrm{~mm}$ and $0.5^{\circ}$ was established for the difference between the first and second observations of linear and angular measurements respectively. If the limit was exceeded, a new tracing and measurements were made. The collected data for the 20 patients was analyzed using SPSS software version (17). For assessment of treatment changes within the groups, a paired sample t. test was performed and unpaired $t$. test was used for the evaluation of changes between the groups. $\mathrm{P} \leq$ 0.05 is considered statistically significant where $\mathrm{P} \leq$ 0.001 is considered statistically highly significant.

\section{RESULTS}

The results of the present study revealed that the age range of group I was $19.78 \pm 1.24$, while it was $18.98+1.16$ in group II with no significant difference between them [table 1].

TABLE (1) Comparison of the mean ages between the mini-implant group (group I) and the conventional anchorage group (group II).

\begin{tabular}{|c|c|c|c|c|c|}
\hline Gps & Pt.No & Mean & \pm SD & T test & P value \\
\cline { 1 - 3 } GI & 10 & 19.78 & \pm 1.24 & \multirow{2}{*}{1.49} & 0.15 \\
\cline { 1 - 3 } GII & 10 & 18.98 & \pm 1.16 & & \\
\hline
\end{tabular}

\section{$P>0.05$ (Non significant)}

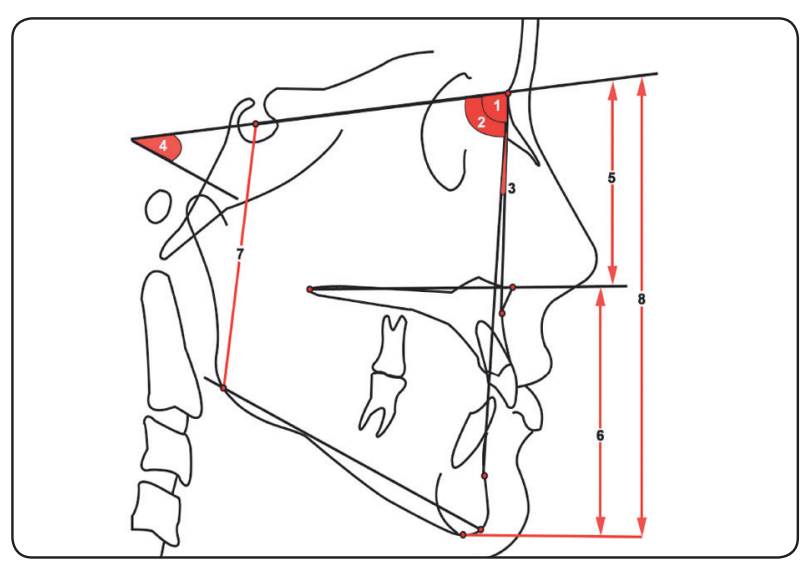

Fig (4) Skeletal measurements

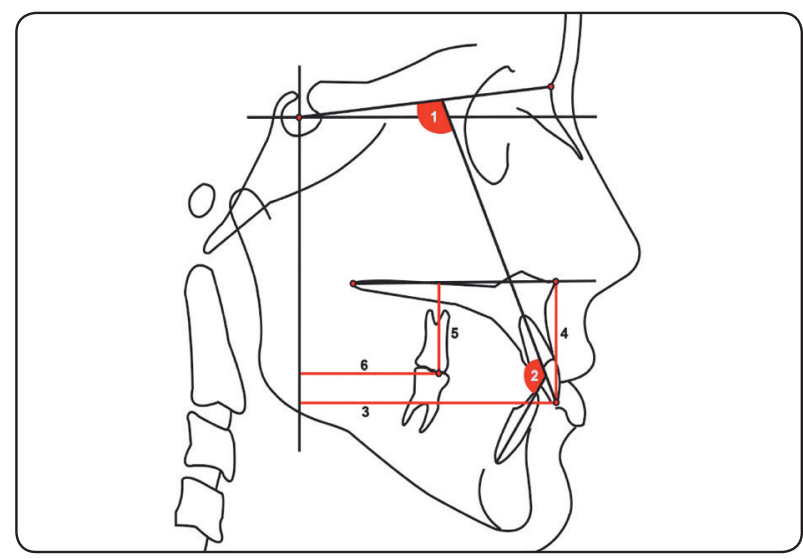

Fig (5) Dental measurements

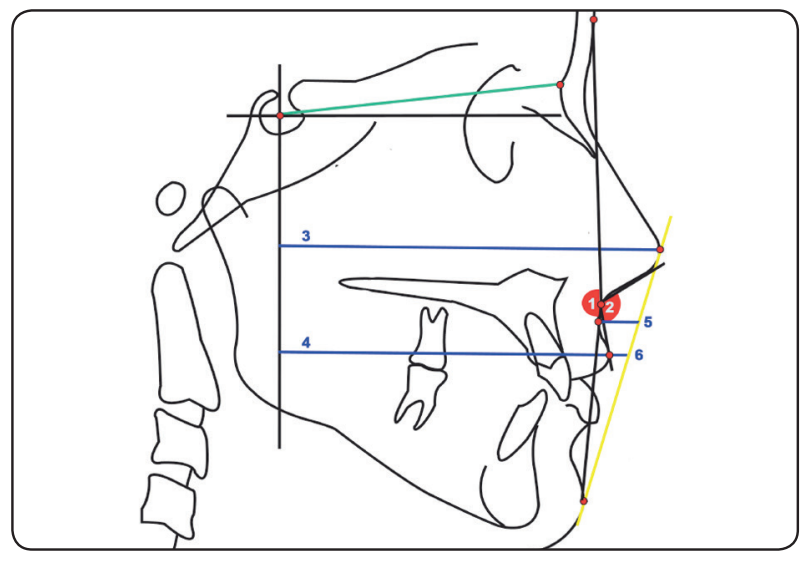

Fig (6) Soft tissue measurements 
The average times required for space closure were $9.69 \pm 2.63$ months in group I and $12.41 \pm$ 2.78 months in group II. The difference between the 2 groups was not statistically significant for the duration of retraction [table 2].

TABLE (2) Comparison of the duration of retraction (in month) between group I and group II.

\begin{tabular}{|c|c|c|c|c|}
\hline Gps & $\begin{array}{c}\text { Mean of retraction } \\
\text { duration }\end{array}$ & $+\mathrm{SD}$ & T test & $\begin{array}{c}\mathrm{P} \\
\text { value }\end{array}$ \\
\hline GI & 9.69 & \pm 2.63 & \multirow{2}{*}{2.08} & 0.052 \\
\hline GII & 12.41 & \pm 2.78 & & \\
\hline
\end{tabular}

$P>0.05$ (Non significant)

The treatment changes for each cephalometric parameter were calculated by subtracting the measurements taken at T1 (pre-retraction) from T2 (post-retraction) measurements. Linear measurements with a negative sign mean distal, backward, or intrusive movement to a relevant reference line, while a positive value indicates a forward, mesial, or extrusive movement. A positive value for change in an angular measurement indicates that the measurement became more obtuse during treatment.

The means and standard deviations of the preretraction and post-retraction measurements are listed for each group. For each cephalometric parameter, comparison of treatment changes (T2T1) between G1 and G2 patients are listed with the associated $\mathrm{P}$ values as determined by the unpaired $\mathrm{t}$ test.

\section{Skeletal measurements}

The lateral cephalometric x- ray analysis of the skeletal measurements in group I revealed that in the anteroposterior changes, there were significant increase in SNB angle $(\mathrm{P}<0.05)$ and a highly significant decrease in SNA and ANB angle $(\mathrm{P}<$
0.001). In the vertical changes, there was high significant reduction in the lower facial height (LFH) and SN-GoGn angle $(\mathrm{P}<0.001)$, while a high significant increase was noted for posterior facial height (PFH) and PFH/TAFH (P < 0.001). Other vertical variables showed no significant changes [table 3].

TABLE (3) Changes in the cephalometric skeletal measurements in group I.

\begin{tabular}{|c|c|c|c|c|}
\hline $\begin{array}{c}\text { Skeletal } \\
\text { measurements }\end{array}$ & Pre-retraction & Post-retraction & t. test & p. value \\
\hline SNA $^{\circ}$ & $83.9 \pm 1.91$ & $82.6 \pm 1.50$ & 6.09 & $0.001^{* *}$ \\
\hline SNB $^{\circ}$ & $75.8 \pm 2.39$ & $76.7 \pm 1.95$ & -2.86 & $0.019^{*}$ \\
\hline ANB $^{\circ}$ & $8.1 \pm 3.07$ & $5.9 \pm 2.56$ & 5.66 & $0.001^{* *}$ \\
\hline SN-MP & $37.2 \pm 4.96$ & $35.3 \pm 4.81$ & 8.14 & $0.001^{* *}$ \\
\hline UFH (mm) & $51.9 \pm 3.17$ & $51.9 \pm 3.21$ & 0.00 & 1.000 \\
\hline LFH (mm) & $71.4 \pm 5.46$ & $70.2 \pm 5.53$ & 4.81 & $0.001^{* *}$ \\
\hline PFH (mm) & $71.7 \pm 7.60$ & $72.9 \pm 7.16$ & -6.00 & $0.001^{* * *}$ \\
\hline TAFH (mm) & $119.1 \pm 6.59$ & $118.1 \pm 6.42$ & 2.02 & 0.074 \\
\hline UFH/LFH \% & $72.99 \pm 6.29$ & $74.17 \pm 6.66$ & -1.91 & 0.088 \\
\hline PFH/TAFH \% & $60.14 \pm 4.72$ & $61.71 \pm 4.74$ & -7.54 & $0.001^{* *}$ \\
\hline LFHAF \% & $59.92 \pm 2.54$ & $59.41 \pm 2.60$ & 1.72 & 0.119 \\
\hline
\end{tabular}

$P>0.05$ (Non significant)

$* P \leq 0.05$ (Significant)

\section{$* * P \leq 0.001$ (Highly significant)}

Table [4] illustrated non-significant differences in any measured skeletal cephalometric parameters between pre-retraction and post-retraction stages except for SNA angle which showed significant decrease $(\mathrm{P}<0.05)$. 
TABLE (4) Changes in the cephalometric skeletal measurements in group II.

\begin{tabular}{|c|c|c|c|c|}
\hline $\begin{array}{c}\text { Skeletal } \\
\text { measurements }\end{array}$ & Pre-retraction & Post-retraction & t. test & p. value \\
\hline SNA $^{\circ}$ & $83 \pm 3.65$ & $81 \pm 2.36$ & 2.58 & $0.03^{*}$ \\
\hline SNB $^{\circ}$ & $76.8 \pm 3.33$ & $76.1 \pm 2.64$ & 1.66 & 0.13 \\
\hline ANB $^{\circ}$ & $6.2 \pm 2.74$ & $4.9 \pm 1.97$ & 1.45 & 0.18 \\
\hline SN-MP $^{\circ}$ & $33.6 \pm 4.88$ & $34.2 \pm 4.59$ & -1.96 & 0.08 \\
\hline UFH (mm) & $50.1 \pm 2.23$ & $50.3 \pm 1.89$ & -0.8 & 0.44 \\
\hline LFH (mm) & $65.9 \pm 5.63$ & $66.1 \pm 6.26$ & -0.51 & 0.62 \\
\hline PFH (mm) & $70.8 \pm 6.34$ & $70.4 \pm 6.15$ & 1.31 & 0.22 \\
\hline TAFH (mm) & $113.5 \pm 6.9$ & $113.6 \pm 7.03$ & -0.26 & 0.8 \\
\hline UFH/LFH \% & $76.44 \pm 6.16$ & $76.63 \pm 6.76$ & -0.27 & 0.79 \\
\hline PFH/TAFH \% & $62.4 \pm 4.47$ & $61.98 \pm 3.96$ & 1.3 & 0.23 \\
\hline LFH/TAFH \% & $57.99 \pm 1.97$ & $58.09 \pm 2.27$ & -0.31 & 0.76 \\
\hline
\end{tabular}

$P>0.05$ (Non significant) $\quad * P \leq 0.05$ (Significant)

**P $\leq 0.001$ (Highly significant)

Regarding cepalometric angular measurements, SNA and ANB angles did not show any significant differences between group I and group II. Comparison of changes with treatment between the two groups showed that SNB was significantly larger $(\mathrm{P}<0.05)$ in group I. Furthermore, closing rotation of the mandible was observed in group I, while opening rotation was seen in group II. The differences regarding the vertical changes between the two studied groups were statistically significant. LFH was decreased in group I $(-1.2 \pm 0.789 \mathrm{~mm}$; $\mathrm{P}<0.001)$ while increased in group II $(0.200 \pm$ $1.229 \mathrm{~mm}$ ) with significant differences between the two groups $(\mathrm{P}<0.05)$. Moreover, $\mathrm{PFH}$ and $\mathrm{PFH} /$ TAFH were increased in group I (1.2 mm and 1.56 $\%$ respectively; $\mathrm{P}<0.001$ ) but decreased in group II $(-0.4 \mathrm{~mm}$ and $-0.42 \%$; $\mathrm{P}<0.05)$ with highly significant differences were recorded intergroup $(\mathrm{P}<0.001)$ [table 5].
TABLE (5) Comparison of the cephalometric skeletal mean changes between group I and group II.

\begin{tabular}{|c|c|c|c|c|}
\hline $\begin{array}{c}\text { Skeletal } \\
\text { measurements }\end{array}$ & G I & G II & t. test & p. value \\
\hline SNA $^{\circ}$ & $-1.3 \pm 0.68$ & $-2 \pm 2.45$ & 0.87 & 0.395 \\
\hline SNB $^{\circ}$ & $0.9 \pm 0.99$ & $-0.7 \pm 1.34$ & 3.04 & $0.007 *$ \\
\hline ANB $^{\circ}$ & $-2.2 \pm 1.23$ & $-1.3 \pm 2.83$ & -0.92 & 0.369 \\
\hline SN-MP & $-1.9 \pm 0.74$ & $0.6 \pm 0.97$ & -6.5 & $0.001 * *$ \\
\hline UFH (mm) & $0.0 \pm 1.25$ & $0.2 \pm 0.79$ & -0.43 & 0.673 \\
\hline LFH (mm) & $-1.2 \pm 0.79$ & $0.2 \pm 1.23$ & -3.03 & $0.007 *$ \\
\hline PFH (mm) & $1.2 \pm 0.63$ & $-0.4 \pm 0.97$ & 4.38 & $0.001^{* *}$ \\
\hline TAFH (mm) & $-1 \pm 1.56$ & $0.1 \pm 1.2$ & -1.77 & 0.094 \\
\hline UFH/LFH \% & $1.19 \pm 1.96$ & $0.19 \pm 2.25$ & 1.05 & 0.307 \\
\hline PFH/TAFH \% & $1.56 \pm 0.65$ & $-0.42 \pm 1.03$ & 5.15 & $0.001^{* *}$ \\
\hline LFH/TAFH \% & $-0.514 \pm 0.94$ & $0.09 \pm 0.95$ & -1.44 & 0.168 \\
\hline
\end{tabular}

\section{Dental measurements:}

The cephalometric analysis of the dental measurements in group I illustrated the anteroposterior and vertical treatment changes in maxillary central incisors and maxillary first molars in group I. In the maxillary incisors movement, clinically significant levels of retraction were achieved for both angular (U1-SN) $\left(-11.6^{\circ}\right.$; P $<0.05)$ and linear $(\mathrm{U} 1-\mathrm{Sv})(-7.8 \mathrm{~mm} ; \mathrm{P}<0.001)$ measurements. In addition, statistically significant amount of intrusion (U1-PP) $(-2.3 \mathrm{~mm} ; \mathrm{P}<0.001)$ was recorded in the mini-implant group. In the maxillary first molars movement, the upper first molars (U6-PP) were intruded in group I (-0.8 mm; $\mathrm{P}<0.05)$. Though no significant distalization of the upper first molars (U6-Sv) was found $(-0.55 \mathrm{~mm}$; $\mathrm{P}<0.05)$, there existed molar distalization in some patients [table 6]. 
TABLE (6) Changes of the cephalometric dental measurements in group I.

\begin{tabular}{|c|c|c|c|c|}
\hline $\begin{array}{c}\text { Dental } \\
\text { measurements }\end{array}$ & $\begin{array}{c}\text { Pre- } \\
\text { retraction }\end{array}$ & $\begin{array}{c}\text { Post- } \\
\text { retraction }\end{array}$ & t. test & p. value \\
\hline${\mathrm{U} 1-S N^{\circ}}^{\circ}$ & $110.9 \pm 6.87$ & $99.3 \pm 9.08$ & 3.22 & $0.004^{*}$ \\
\hline $\mathrm{U} 1-L 1^{\circ}$ & $120.5 \pm 11.43$ & $138 \pm 9.03$ & -5.06 & $0.001^{* *}$ \\
\hline $\mathrm{U} 1-\mathrm{Sv} \mathrm{mm}$ & $81.8 \pm 3.36$ & $74 \pm 3.06$ & 9.92 & $0.001^{* *}$ \\
\hline $\mathrm{U} 1-P P \mathrm{~mm}$ & $31.6 \pm 3.03$ & $29.3 \pm 2.79$ & 6.87 & $0.001^{* *}$ \\
\hline U6-PP mm & $25.9 \pm 2.69$ & $25.1 \pm 2.69$ & 2.75 & $0.022^{*}$ \\
\hline U6-Sv mm & $42.2 \pm 3.05$ & $41.65 \pm 3.33$ & 1.38 & 0.200 \\
\hline
\end{tabular}

$P>0.05$ (Non significant)

$* P \leq 0.05$ (Significant)

** $P \leq 0.001$ (Highly significant)

The results presented in Table [7] showed that showed that, in the maxillary incisors movement, it was noted that, the upper incisor edges were significantly retracted $\left(\mathrm{U} 1-\mathrm{SN}=-17.5^{\circ} ; \mathrm{P}<0.001\right)$ $(\mathrm{U} 1-\mathrm{Sv}=-5.5 \mathrm{~mm} ; \mathrm{P}<0.001)$ and extruded (U1-PP $=1.1 \mathrm{~mm} ; \mathrm{P}<0.05)$. In the maxillary first molars movement, highly significant amounts of anchorage loss were noted in both vertical (U6-PP $=0.95 \mathrm{~mm}$; $\mathrm{P}<0.001)$ and horizontal (U6-Sv $=2.2 \mathrm{~mm}$; $\mathrm{P}<$ 0.001) directions.

TABLE (7) Changes of the cephalometric dental measurements in group II.

\begin{tabular}{|c|c|c|c|c|}
\hline $\begin{array}{c}\text { Dental } \\
\text { measurements }\end{array}$ & Pre-retraction & $\begin{array}{c}\text { Post- } \\
\text { retraction }\end{array}$ & t. test & p. value \\
\hline${\mathrm{U} 1-S N^{\circ}}^{\circ}$ & $114.1 \pm 4.04$ & $96.6 \pm 5.84$ & 10.98 & $0.001 * *$ \\
\hline $\mathrm{U} 1-L 1^{\circ}$ & $116.2 \pm 7.63$ & $138.5 \pm 9.48$ & -13.02 & $0.001 * *$ \\
\hline $\mathrm{U} 1-\mathrm{Sv} \mathrm{mm}$ & $79.8 \pm 4.44$ & $74.3 \pm 4.32$ & 8.88 & $0.001 * *$ \\
\hline $\mathrm{U} 1-\mathrm{PP} \mathrm{mm}$ & $29.4 \pm 3.37$ & $30.5 \pm 4.25$ & -2.91 & $0.017 *$ \\
\hline $\mathrm{U} 6-\mathrm{PP} \mathrm{mm}$ & $24.65 \pm 2.33$ & $25.6 \pm 2.32$ & -6.04 & $0.001 * *$ \\
\hline $\mathrm{U} 6-\mathrm{Sv} \mathrm{mm}$ & $39.3 \pm 4.9$ & $41.5 \pm 4.74$ & -5.66 & $0.001 * *$ \\
\hline
\end{tabular}

$P>0.05$ (Non significant)

$* P \leq 0.05$ (Significant)
Comparing the cephalometric dental measurements between the two studied groups revealed significant differences in the horizontal and vertical movement of maxillary central incisors and maxillary first molars. In the maxillary incisors movement, when considering the amount of retraction of upper incisors in both groups (U1$\mathrm{Sv}$ ), it was greater in group I than in group II by 2,3 $\mathrm{mm}$, and the difference was statistically significant $(\mathrm{P}<0.05)$. Whereas, U1-SN angle and interincisal angle $\left(\mathrm{U} 1-\mathrm{L}^{\circ}{ }^{\circ}\right)$ exhibited no significant differences between the two groups $(\mathrm{P}>0.05)$. The obtained results showed that, the upper incisors (U1-PP) were intruded in group I $(-2.3 \pm 1.059 \mathrm{~mm})$ but they were extruded in group II $(1.100 \pm 1.197 \mathrm{~mm})$ with a high significant difference between the two groups $(\mathrm{P}<0.001)$. In the maxillary first molars movement, there were net intrusion (U6-PP $=-0.800$ $\pm 0.919 \mathrm{~mm})$ and distal movement (U6-Sv $=-0.55 \pm$ $1.257 \mathrm{~mm}$ ) of the upper first molars in group I. The differences were highly significant when compared with group II which had extrusion (U6-PP $=0.950$ $\pm 0.497 \mathrm{~mm}$ ) and mesial movement (U6-Sv $=2.200$ $\pm 1.229 \mathrm{~mm}$ ) for the same measurements [table 8]

TABLE (8) Comparison of the cephalometric dental mean changes between groups I and II.

\begin{tabular}{|c|c|c|c|c|}
\hline $\begin{array}{c}\text { Dental } \\
\text { measurements }\end{array}$ & GI & GII & t. test & p. value \\
\hline${\mathrm{U} 1-S N^{\mathrm{o}}}^{-}$ & $-11.6 \pm 7.62$ & $-17.5 \pm 5.04$ & 2.03 & 0.06 \\
\hline${\mathrm{U} 1-\mathrm{L} 1^{\circ}}^{\circ}$ & $17.5 \pm 10.94$ & $22.3 \pm 5.42$ & -1.24 & 0.23 \\
\hline $\mathrm{U} 1-\mathrm{Sv} \mathrm{mm}$ & $-7.8 \pm 2.49$ & $-5.5 \pm 1.96$ & -2.29 & $0.034^{*}$ \\
\hline $\mathrm{U} 1-\mathrm{PP} \mathrm{mm}$ & $-2.3 \pm 1.06$ & $1.1 \pm 1.19$ & -6.73 & $0.001^{* *}$ \\
\hline $\mathrm{U} 6-\mathrm{PP} \mathrm{mm}$ & $-0.8 \pm 0.92$ & $0.95 \pm 0.49$ & -5.32 & $0.001^{* *}$ \\
\hline $\mathrm{U} 6-\mathrm{Sv} \mathrm{mm}$ & $-0.55 \pm 1.26$ & $2.2 \pm 1.23$ & -4.95 & $0.001^{* *}$ \\
\hline
\end{tabular}

P> 0.05 (Non significant)

$* P \leq 0.05$ (Significant)

$* * P \leq 0.001$ (Highly significant) 


\section{Soft tissue measurements:}

In the profile changes, a significant decrease in the facial convexity angle $\left(\mathrm{G}-\mathrm{Sn}-\mathrm{Pog} 1^{\circ}\right)$ was noted in group I $(\mathrm{P}<0.05)$. Nasolabial angle and the sagittal position of the most anterior point of the nose (Nt$\mathrm{Sv})$ showed high significant increase $(\mathrm{P}<0.001)$. For the upper lip changes, statistically significant level of lip retraction was seen as demonstrated by linear measurements (Ls -Sv, E line-Ss and E lineLs) $(\mathrm{P}<0.001)$ [table 9].

TABLE (9) Changes in the cephalometric soft tissue measurements in group I.

\begin{tabular}{|c|c|c|c|c|}
\hline $\begin{array}{c}\text { Soft tissue } \\
\text { measurements }\end{array}$ & Pre-retraction & $\begin{array}{c}\text { Post- } \\
\text { retraction }\end{array}$ & t. test & p. value \\
\hline $\begin{array}{c}\text { G-Sn-Pog\ } \\
\text { Nasolabial }^{\text {angle }}{ }^{\circ}\end{array}$ & $159.1 \pm 6.57$ & $157.5 \pm 6.24$ & 2.67 & $0.026^{*}$ \\
\hline Nt-Sv mm $^{*}$ & $96.9 \pm 5.55$ & $113.5 \pm 6.13$ & -5.32 & $0.001^{* *}$ \\
\hline Ls-Sv mm & $85 \pm 3.23$ & $79.7 \pm 3.13$ & 11.22 & $0.001^{* *}$ \\
\hline E line- Ss mm & $-8.6 \pm 2.07$ & $-10 \pm 1.7$ & 5.25 & $0.001^{* *}$ \\
\hline E line- Ls mm & $0.3 \pm 3.37$ & $-3.4 \pm 3.66$ & 6.62 & $0.001^{* *}$ \\
\hline
\end{tabular}

$P \leq 0.05$ (Significant)

$* * P \leq 0.001$ (Highly significant)

Similar to group I, group II showed statistically significant increase in the nasolabial angle $(\mathrm{P}<0.05)$ and statistically significant backward retraction of the upper lip relative to SV and $\mathrm{E}$ lines $(\mathrm{P}<0.001)$ [table 10].

TABLE (10) Changes in the cephalometric soft tissue measurements in group II.

\begin{tabular}{|c|c|c|c|c|}
\hline $\begin{array}{c}\text { Soft tissue } \\
\text { measurements }\end{array}$ & Pre-retraction & $\begin{array}{c}\text { Post- } \\
\text { retraction }\end{array}$ & t. test & p. value \\
\hline $\mathrm{G}-\mathrm{Sn}-\mathrm{Pog} \backslash^{\circ}$ & $163.2 \pm 7.35$ & $162.8 \pm 7.3$ & 0.39 & 0.702 \\
\hline $\begin{array}{c}\text { Nasolabial } \\
\text { angle }^{\circ}\end{array}$ & $91.4 \pm 7.73$ & $98 \pm 4.35$ & -3.52 & $0.007 *$ \\
\hline $\mathrm{Nt}-\mathrm{Sv} \mathrm{mm}$ & $92.3 \pm 4.29$ & $92.5 \pm 4.55$ & -0.69 & 0.509 \\
\hline Ls-Sv mm & $81.8 \pm 4.05$ & $78.6 \pm 4.4$ & 4.82 & $0.001 * *$ \\
\hline E line- Ss mm & $-8.8 \pm 2.2$ & $-9.9 \pm 2.13$ & 1.77 & 0.111 \\
\hline E line- Ls mm & $0.7 \pm 3.95$ & $-1.1 \pm 2.96$ & 2.59 & $0.029 *$ \\
\hline
\end{tabular}

$P>0.05$ (Non significant)

$* P \leq 0.05$ (Significant)

$* * P \leq 0.001$ (Highly significant)
Comparison of soft tissue changes between groups I and II revealed that, the profile changes were more prominent in the group I than in the group II. Facial convexity angle (G-Sn-Pog $\left.1^{\circ}\right)$ was decreased in both groups $\left(-1.600 \pm 1.897^{\circ}\right)$ for group I and $\left(-0.400 \pm 3.204^{\circ}\right)$ for group II, but the intergroup differences were not statistically significant $(\mathrm{P}>$ 0.05). The nasolabial angle was increased for both groups but the increase was significantly greater for group I $(\mathrm{P}<0.05)$. For the upper lip changes, statistically significant levels of retraction (Ls-Sv) were seen for both groups ( $\mathrm{P}<0.001)$, but group I showed a statistically greater level of upper lip retraction $(-5.300 \pm 1.494 \mathrm{~mm})$ than did group II $(-3.200 \pm 2.098 \mathrm{~mm})(\mathrm{P}<0.05)$. In addition, $\mathrm{E}$ lineLs was decreased more in group I $(-3.7 \pm 1.767$ $\mathrm{mm} ; \mathrm{P}<0.001)$ than in group II $(-1.8+2.201 \mathrm{~mm} ; \mathrm{P}$ $<0.05)$ with a significant difference between the two groups $(\mathrm{P}<0.05)$ [table 11].

TABLE (11) Comparison of the cephalometric soft tissue mean changes between groups I and II.

\begin{tabular}{|c|c|c|c|c|}
\hline $\begin{array}{c}\text { Soft tissue } \\
\text { measurements }\end{array}$ & GI & GII & t. test & p. value \\
\hline G-Sn-Pog $\searrow^{\circ}$ & $-1.6 \pm 1.89$ & $-0.4 \pm 3.2$ & $\mid-1.27$ & 0.222 \\
\hline $\begin{array}{l}\text { Nasolabial } \\
\text { angle }^{\circ}\end{array}$ & $13.6 \pm 8.09$ & $6.6 \pm 5.93$ & 2.21 & $0.040^{*}$ \\
\hline Nt-Sv mm & $0.9 \pm 0.57$ & $0.2 \pm 0.92$ & 2.05 & 0.055 \\
\hline Ls-Sv mm & $-5.3 \pm 1.49$ & $-3.2 \pm 2.1$ & -2.58 & $0.019 *$ \\
\hline $\mathrm{E}$ line- $\mathrm{Ss} \mathrm{mm}$ & $-1.4 \pm 0.84$ & $-1.1 \pm 1.97$ & 0.07 & 0.094 \\
\hline E line- Ls $\mathrm{mm}$ & $-3.7 \pm 1.77$ & $-1.8 \pm 2.2$ & -2.13 & $0.047 *$ \\
\hline
\end{tabular}

$P>0.05$ (Non significant)

$* P \leq 0.05$ (Significant) 


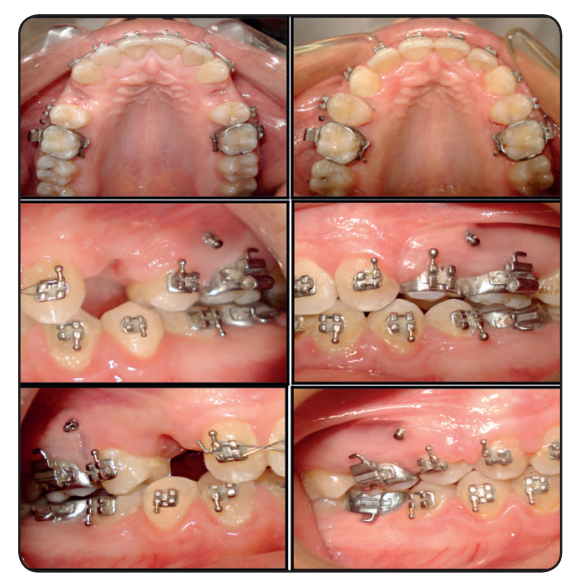

Fig (7) Case number (1) intraoral lateral view: A and B (just before en-masse retraction): $\mathrm{C}$ and $\mathrm{D}$ (immediately after closure of the extraction space using en-masse retraction and mini-implant anchorage)

\section{Case report}

The following figure (7) shows intra-oral occlusal and lateral view: $\mathrm{A}$ and $\mathrm{B}$ (just before en-masse retraction): $\mathrm{C}$ and $\mathrm{D}$ (immediately after closure of the extraction space using en-masse retraction and mini-implant anchorage). Figure (8) shows intraoral occlusal and lateral view: A, B, and C (just before canine retraction): D, E and F (immediately after closure of the extraction space using conventional anchorage mechanics).

\section{DISCUSSION}

Anchorage control in sever skeletal class II patients is a difficult problem in orthodontic treatment. In adults, treatment of class II malocclusion often requires premolar extractions and maximum anchorage ${ }^{[13]}$.

Extraoral and intraoral appliances, such as headgear, transpalatal arch, and Nance holding appliance, are commonly incorporated into the treatment mechanics of class II malocclusions to reinforce the maxillary posterior anchorage, most likely followed by class II elastics worn to retract the maxillary anterior teeth and mesialize the mandibular posterior teeth. However, extrusion

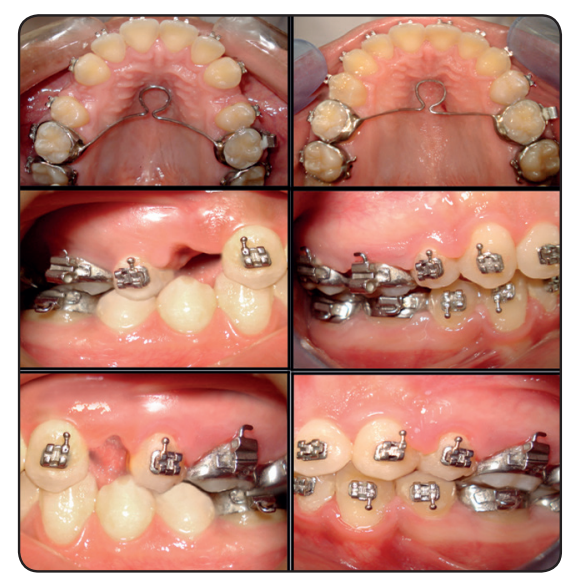

Fig (8) Case number (2) intraoral lateral view: A and B (just before canine retraction): $\mathrm{C}$ and $\mathrm{D}$ (immediately after closure of the extraction space using conventional anchorage mechanics)

of the mandibular molars is often observed when a patient wears class II elastics. This side effect can have a negative impact on the correction of class II malocclusion, especially for those with facial hyperdivergency ${ }^{[5]}$. In addition, it is widely recognized that these conventional anchorage systems are limited by multiple factors such as patients' compliance, discomfort, and anchorage loss ${ }^{[19]}$.

With the advantages of less archwire bending and more patients' comfort, sliding mechanics for en-masse retraction of anterior teeth is often used with increased utilization of pre-adjusted appliances ${ }^{[20]}$. However, it may cause anchorage loss because of the attempts to retract six anterior teeth simultaneously and the tip built into anterior brackets, tending to push anterior teeth forward during initial alignment and leveling. Therefore, TSADs, aiming for absolute anchorage, were used to prevent anchorage loss ${ }^{[21,22]}$.

Mini-implants, unlike conventional orthodontic implants, can be placed in a great variety of locations in the maxilla and the mandible because of their small sizes to provide absolute anchorage which eliminates undesirable effects on the teeth that otherwise would have been used as anchorage ${ }^{[17]}$. 
As the placement and removal of mini-implants does not require a particular surgical procedure as in conventional orthodontic implants, miniplates and onplants, so they were used as temporary anchorage devices. Moreover, they can be easily placed at chair side in one appointment by the orthodontist with no need for complicated clinical procedures to facilitate safe and precise implant placement or to connect it with the teeth. Furthermore, patient cooperation is limited to maintaining oral hygiene, and cost is relative if compared with other conventional methods used for anchorage, and much lower than orthodontic implants. So, it has gained enormous credibility in the clinical management of space closure $^{[6,23,24 \text { and } 25]}$.

The purpose of the present study was to compare the skeletal, dental, and soft tissue treatment outcomes between sliding en-masse retraction of maxillary anterior teeth employing mini-implants and the two-step sliding retraction approach employing conventional anchorage in patients with class II division 1 malocclusion.

In the present study, a sample of 20 patients with class II division 1 malocclusion were randomly assigned either to group I, mini-implants was used for sliding en-masse retraction of maxillary anterior teeth, or group II, conventional methods of anchorage reinforcement were used for twostep retraction of maxillary anterior teeth. The patients' ages ranged from eighteen to twenty four years to eliminate the effect of growth which could be misdiagnosed as loss of anchorage. All of them required therapeutic extraction of maxillary first premolars, with subsequent retraction of the maxillary anterior teeth.

Although different dimensions of mini-implants had been used by several authors [15, 16, 18, 26 and 27], in the present study, $1.3 \mathrm{~mm}$ diameter and $8 \mathrm{~mm}$ long mini-implants were selected to optimize the mechanical retention of the mini-implants and to eliminate any risks of root proximity or contact that might contribute to failure during treatment ${ }^{[28-30]}$.
In the current study, the inciso-appical implantation site was the mucogingival junction. This site proved to be clinically accessible for implantation of mini-implants without the need to incise the mucosa or reflect a mucoperiosteal flap that flapless implantation allows for simple attachment between the exposed head and the orthodontic appliance. Additionally, it provided adequate cortical bone thickness which ensures better primary stability and long term success of the

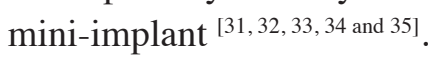

The placement site of mini-implants between the maxillary second premolars and the first molars provides easier accessibility and better oral hygiene maintenance as there is enough space for implantation. Also, bone availability in this region enhances mechanical retention of mini-implants, and this would be subsequently reflected on a higher success rate ${ }^{[28 \text { and } 36]}$.

The distance between the roots of the maxillary second premolar and first molar was $3.18 \mathrm{~mm}$ at five to seven mm apical from the alveolar crest, and the apices of the mini-implants were usually placed into the alveolar bone more apical than the five to seven $\mathrm{mm}$ level. By placing mini-implants at $30-60^{\circ}$ to the bone surface of the maxillary arch, the apices of the mini-implants can be kept apart from the roots. Therefore, the possibility of damage to the roots could be eliminated. Also, contact with the cortical bone would increase by as much as 1.5 times compared with placement at 90 degree. Therefore, enhances primary mini-implant stability [37,38 and 39].

Mini-implants were immediately loaded after placement, with the belief that, a waiting period is not necessary for mini-implants because their primary stability (mechanical retention) is sufficient to sustain normal orthodontic loading, and this would not compromise the clinical stability of the mini-implants and do not decrease their stability. Moreover, immediate loading which simulates bone formation could be beneficial due to the fact that only unloaded control mini-implants showed mobility [40 and 41$]$. 
The choice of the nickel-titanium closed coil spring as the retraction mean was due to the fact that, it permits constant force application over a wide range of activation. Also, for stability of the mini-implant and for efficient tooth movement, light continuous forces as generated by the nickel-titanium closed coil springs are preferred over elastomerics, which often generate an excessive initial force. In addition, elastomerics become permanently deformed after absorbing water and saliva when exposed to the oral environment for extended periods. This actually results in loss of force because of stress relaxation of the elastomerics ${ }^{[15,42,43]}$.

The forces exerted with implants for en-masse retraction were within the physiologic limits (150-200gms/side), because precalibrated nickeltitanium coil springs were used. In addition, due to the group movement of the teeth, forces were equally distributed along the root surface area and thus did not concentrate at one point ${ }^{[6 \text { and } 44]}$.

Rigid rectangular arch wires $(0.017 \times 0.025$ inch stainless steel archwire) in the 0.022 inch bracket system produces less friction than the 0.019 X 0.025 inch archwire and hence facilitated faster tooth movement ${ }^{[45]}$. Also, Basha et al., 2010 ${ }^{[46]}$ believed that, the anterior inclination was dictated by the control of force direction, the torquing curve on the archwire and retraction of six anterior teeth with sliding mechanics. So the need for heavy archwire decreased.

Placement of the power arm of an archwire between the lateral incisor and canine enables orthodontists to maintain better control of the anterior teeth in sliding mechanics ${ }^{[44]}$.

Soft tissue overgrowth was minimized in the current study by partial insertion, leaving two or three threads of the mini-implant out of the bone. Thus hygiene could be easily maintained ${ }^{[47]}$.

In the present study, there was no loosening of the mini-implants during the active retraction of the maxillary anterior teeth. Similar finding was reported by Thiruvenkatachari et al., $2006^{[12]}$.
On the other hand Garfinkle et al., $2008^{[48]}$ reported $51 \%$ success rate while $\mathbf{W u}$ et al., $2009^{\left({ }^{(128)}\right.}$ reported $90 \%$ success rate.

Only pre-retraction (T1) and immediately after space closure (T2) cephalograms (rather than pretreatment and posttreatment cephalograms) were included in the study for a minimal time difference between the two sets records and to estimate treatment change primarily due to retraction of anterior teeth ${ }^{[26]}$.

The duration of retraction in mini-implant group $(9.6 \pm 2.63$ months) was close to the value obtained by Upadhyay et al., $2008^{[6]}$ and Upadhyay et al., $2009{ }^{\text {[49] }}$ (9.2 months, 9.4 months) respectively.

However, longer retraction periods (15.4 months, 13.94 months, 17 months and 10 months) were

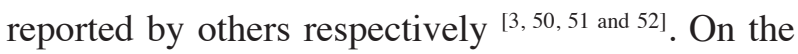
other hand, Erverdi and Acar, $2005^{[53]}$, Kokitsawat

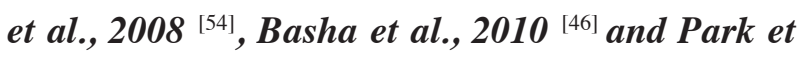
al., 2012 ${ }^{[55]}$ reported shorter retraction periods (6 months, 5.23 months, 6.03 months and 8.7 months) respectively. This could be explained by difference in the retraction mechanics. Also, difference in the retraction force could play role.

In the present study, the difference between the two groups was not statistically significant for the retraction period. A similar finding was reported by Benson et al., $2007^{[56]}$, Feldmann and Bondemark,

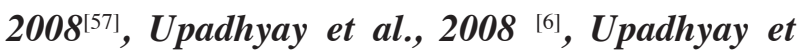

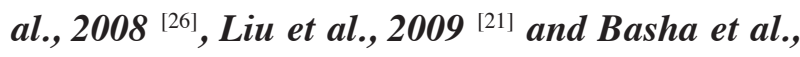
2010 ${ }^{[46]}$. A possible explanation could be that, in mini-implant group, closure of the extraction space was completely done by distalization of anterior teeth. Whereas, in the nonimplant group due to anchorage loss, there was simultaneous movement of anterior and posterior teeth into the extraction space $^{[3,26,46]}$.

On contrast Park and Kwon, $2004^{[22]}$, Huang

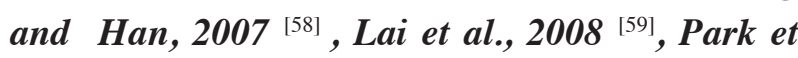
al., $2008^{[60]}$, Yao et al., $2008^{[5]}$, Park et al., 2012 ${ }^{[55]}$ and Sibaie and Hajeer, $2014{ }^{[27]}$ found that, 
en-masse retraction of the six anterior teeth on miniimplant, instead of step-by-step retraction of the canine and four incisors can shorten the treatment duration significantly and allows an early change of the facial profile.

It was found that $\mathrm{SNA}^{\circ}$ was significantly decreased in both groups. However, $\mathrm{ANB}^{\circ}$ was significantly decreased in group I only. These results were in agreement with Liu et al., $2009^{[21]}$ and Jee et al., 2014 ${ }^{[61]}$ who reported that, decrease in $\mathrm{SNA}^{\circ}$ occurs because of backward movement of A point following upper anterior teeth retraction. Whereas, $\mathrm{ANB}^{\circ}$ was decreased in group I only because $\mathrm{SNB}^{\circ}$ was increased following anticlockwise rotation of the mandible in mini-implant group.

Contradictory to the finding of the present study, Lee et al., $2001^{[62]}$, Park et al., $2008^{[60]}$, Yao et al., $2008^{[5]}$ and Upadhyay et al., $2009{ }^{[49]}$ reported that, despite extensive retraction of the upper anterior teeth, there was no change or there was a slight increase in the $\mathrm{SNA}^{\circ}$. Probably this controversy resulted from insufficient torque control over the upper incisors during retraction.

By comparing the treatment changes between the two studied groups, it was found that, significant decrease in $\mathrm{SN}^{-\mathrm{MP}^{\circ}}$ was observed in group I in comparison to group II which show non significant increase. This result was supported by the previous finding of Park and Kwon, $2004^{[22]}$, Yao et al., $2008^{[5]}$, Liu et al., $2009^{[21]}$, Koyama et al., 2011 ${ }^{[63]}$ and Lee et al., $2013{ }^{[64]}$ who explained that, intrusion of molars is known to influence closing rotation of the mandible which is favorable for class II correction while opening rotation of the mandible might have occurred as a result of molar extrusion. Although the maxillary molars showed less amount of intrusion in group I, it was sufficient to cause some autorotation of the mandible. It is well known that, only $1 \mathrm{~mm}$ of intrusion of posterior teeth can produce 3-4 $\mathrm{mm}$ of upward and forward movement of the chin ${ }^{[65]}$.
There was an overall decrease in the anterior facial vertical dimension and increase in the posterior facial vertical dimension in group I. These results were matched with those of Upadhyay et al., $2008^{[26]}$ and Upadhyay et al., $2010^{[66]}$ who explained decrease in $\mathrm{LFH}$ and $\mathrm{SN}^{-\mathrm{MP}^{\circ}}$ in miniimplant group were attributed to intrusion of the molars, causing decrease in anterior facial vertical dimension. Small vertical changes at the posterior teeth can produce profound changes in the anterior dimension.

In group II, no significant change in the vertical dimension was noted inspite of significant mesial movement of the upper molars. This result was supported by Lee et al., 2013 ${ }^{[64]}$ who suggested the limitation of conventional anchorage to significantly alter skeletal vertical dimension. According to Staggers, $\quad 1990^{[67]}$ even though the molar moves forward in premolar extraction patients, the vertical dimension of the face is maintained by extrusion of the posterior teeth. A similar concept was stated by Cusimano et al., $1993^{[68]}$ that mesial movement of the posterior teeth coincided with their extrusion to such an extent that they maintained the mandibular plane angle, thus nullifying the bite-closing effect of posterior protraction. This perhaps explained the constancy of facial dimensions in $\mathrm{G} 2$, in which both extrusion and protraction of molars were recorded.

Both studied groups showed significant increase in interincisal angle and significant decrease in inclination and anteroposterior position of upper incisors. This study revealed that, upper incisors showed $99.3^{\circ} \pm 9.08^{\circ}$ with the anterior cranial base at the end of the retraction stage in the miniimplant group, whereas, they were more palatally tipped in the conventional anchorage group $\left(96.6^{\circ} \pm\right.$ $\left.5.84^{\circ}\right)$. Smaller reduction of U1-SN angle in group I $\left(-11^{\circ} \pm 7.66^{\circ}\right)$ than in group II $\left(-17.5^{\circ} \pm 5.04^{\circ}\right)$ may indicate a larger amount of bodily retraction with mini-implant than with conventional anchorage mechanics. These results agreed with that published by Huang and Han, 2007 [58], Ma et al., $2008^{[32],}$

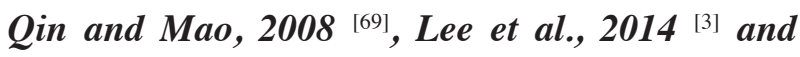


Sibaie and Hajeer, $2014^{[27]}$ who emphasized that, the maxillary incisors were slightly more upright at the end of treatment with conventional anchorage mechanics than with mini-implant. Possible explanation for this may be that, in the miniimplant group, the retraction force was applied near the center of resistance of the maxillary anterior teeth, which is impossible to achieve when the force axis passes along the basic archwire as occurred in the conventional anchorage group.

Therefore, the maxillary anterior teeth were retracted and achieved good inclination to the SN line in group I. But how much ever higher the implants were placed, force application in anterior region will always be below the centre of resistance, therefore, there will be always tipping. As the point of force application moves apically, amount of lingual tipping is slightly reduced and amount of

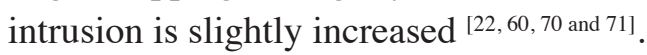

The amount of retraction of upper anterior teeth as demonstrated by linear measurement (U1-Sv) was greater in G1 (-7.8 $\mathrm{mm})$ than in G2 (-5.5 mm). It was coincident with the molar anteroposterior position changes showing a better anchorage control using mini-screw implants than conventional anchorage mechanics. These results matched with those of $\mathbf{L a i}$ et al., $2008^{[59]}$, Upadhyay et al., $2008^{[6]}$,Yao et al., $2008^{[5]}$, Liu et al., $2009^{[21]}$, Kuroda et al., $2009^{[13],}$ Park et al., $2012^{[55]}$, Lee et al., $2013^{[64]}$ and Sibaie and Hajeer, $2014^{[27]}$ who reported more distal movement of upper incisors in mini-implant group $(6.9 \mathrm{~mm}-6.23 \mathrm{~mm}-8.17 \mathrm{~mm}-7.03 \mathrm{~mm}-9.3 \mathrm{~mm}-$ $6.9 \mathrm{~mm}-6.87 \mathrm{~mm}-5.92 \mathrm{~mm}$ ) respectively than those of conventional anchorage group $(5.5 \mathrm{~mm}-5.72 \mathrm{~mm}$ $6.73 \mathrm{~mm}-4.76 \mathrm{~mm}-\quad 6.3 \mathrm{~mm}-\quad 5.3 \mathrm{~mm}-\quad 4.5 \mathrm{~mm}-$ $4.79 \mathrm{~mm}$ ) respectively.

On the other hand, this result contradicted that of Feldmann and Bondemark, $2008^{[57]}$ who found no significant difference between the implant group and conventional anchorage group in terms of incisor retraction. This difference could be possibly result from imbalanced distribution of the study sample in the two anchorage groups and difference in their demands for orthodontic anchorage which ranged from moderate to maximum ${ }^{[57]}$.

Statistically significant level of intrusion was observed for the maxillary incisors in group I $(-2.3 \pm 1.05 \mathrm{~mm})$, while a small amount of extrusion was found when conventional anchorage mechanics were used in group II $(+1.1 \pm 1.19 \mathrm{~mm})$. This finding was in accordance with Ma et al., $2008^{[32]}$, Yao et al., $2008^{[5]}$, Upadhyay et al., $2009^{[49]}$, Kim et

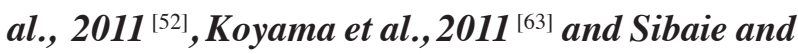
Hajeer, $2014^{[27]}$.

Traditionally, sliding mechanics with conventional anchorage to close the extraction space would cause the upper anterior teeth to move backward and downward, deepening the overbite ${ }^{(35)}$

Other studies ${ }^{[34.49,55 \text { and } 64]}$ showed $1.3 \mathrm{~mm}, 1.8$ $\mathrm{mm}, 3 \mathrm{~mm}$ and $1.54 \mathrm{~mm}$ intrusion of the maxillary central incisors respectively, in class II division 1 patients treated with orthodontic mini-implants to retract the maxillary anterior teeth.

Park and Kwon, $2004^{[22]}$, Shu et al., $2011^{[15]}$ and Upadhyay et al., 2012 ${ }^{[72]}$ explained the reasons for anterior teeth intrusion with the use of mini-implant as skeletal anchorage device. They demonstrated that, the occlusogingival position of mini-implants at the mucogingival junction about $8-10 \mathrm{~mm}$ apical to the bracket slot and the vertical height of the crimpable hook which play a defining role in directing the retraction force upward and backward. The force exerted by the nickel-titanium coil springs (bilaterally) had two distinct components: a larger and predominantly retractive force and a smaller vertical intrusive force, causing en-masse retraction and some intrusion of the anterior teeth. By reducing the height of the crimpable hook, greater intrusion can be achieved. The intrusion of the incisal edges of maxillary incisors was beneficial to counterclockwise rotation of the mandibular plane because the incisal stop is moved farther up ${ }^{[32,66]}$.

In the previous study of Park et al., 2008 ${ }^{[60]}$, there were no significant differences in the 
vertical measurements of the maxillary incisors between patients treated with titanium screws and conventional anchorage technique. In contrast, Araujo et al., 2011 ${ }^{[40]}$ reported $0.33 \mathrm{~mm}$ extrusion of upper incisors during en-masse retraction movement of the upper anterior teeth aided with mini-implant. This might be explained by applying the retraction force parallel to the occlusal plane from the titanium screws to long arm hooks soldered on the archwire.

Furthermore, the upper first molars were intruded in group I but extruded in group II. Similar results were obtained in a clinical cephalometric studies involving en-masse retraction of maxillary anterior teeth with micro-implant anchorage ${ }^{[5,6,63,64]}$.

The probable explanation for molar intrusion obtained in group I in the present study might be that, sliding mechanics with absolute anchorage produced rotation of the entire dentition around the centre of resistance, and the vertical intrusive force acts on the molars if the line of retraction force is exerted below the centre of resistance ${ }^{[73]}$. The centre of resistance for the entire maxillary dentition is approximately halfway from the root apex to the alveolar bone crest between the first and second premolars ${ }^{[74]}$. Therefore, the maxillary molar tended to intrude in the implant anchorage group because the line of retraction force was exerted below the centre of resistance of the maxillary dentition.

In addition, Upadhyay et al., $\quad 2010{ }^{[66]}$ and Upadhyay et al., $2012{ }^{[72]}$ attributed molar intrusion with mini-implant anchorage to the retraction force on the upper arch that was directed upward and backward, producing a small intrusive and a larger distal force on the anterior segment. During space closure, the intrusive force increased because of an increase in the angulation of the applied forces to the occlusal plane. This increase in the vertical component of the total force can cause binding of the stainless steel archwire with the brackets, thereby preventing sliding and resulting in the transmission the force to the entire archwire. This might have produced the distal and intrusive force on the posterior teeth.
In the present study, significant difference in anteroposterior movements of the upper first molars was found between mini-implant and conventional anchorage groups. It was demonstrated that, miniimplants behaved as ankylosd teeth providing not only an absolute anchorage but also distal movement $(-0.55 \pm 1.26 \mathrm{~mm})$ of the upper first molars (anchorage gain) in group I, whereas, the upper first molars in conventional anchorage group showed mesial movement $(2.2 \pm 1.23 \mathrm{~mm})$. Many studies ${ }^{[22,40,51,63,75,76]}$ emphasized stability of the upper first molars in the horizontal and vertical direction during mass retraction of the upper anterior teeth using orthodontic mini-implants as anchorage. Other studies ${ }^{[6,26,49,77]}$ showed distal first molar migration in mini-implant anchorage group of (0.45 mm- $1 \mathrm{~mm}-0.78 \mathrm{~mm}-0.55 \mathrm{~mm})$ respectively. Although it was minimal, this distal movement was attributed to the retraction force applied to the anterior teeth which was translated to the posterior teeth through the friction between buccal tube and archwires. In addition, once the extraction space was closed, the contact between the canine and second premolar was established. At this point any further continuation of the retraction force resulted in its transmission to the posterior segments through the interdental contacts ${ }^{[6,26,49,77]}$.

Surprisingly, some papers ${ }^{[5,13,50,51,60,64,78]}$ reported a mesial movement of the upper molars despite the use of mini-implants as an anchorage tool. This may be due to the use of retraction utility archwires directly supported by mini-implants without engaging the upper molars in active treatment ${ }^{[50]}$, the physiological mesial movement that occurred after early extraction of the upper first premolars at the beginning of the treatment with a delayed initiation of the retraction process ${ }^{[5,13,51,60]}$, difference in the retraction mechanics ${ }^{[64]}$, or may be due to how the patients were selected for the study inclusion ${ }^{[78]}$.

The conventional anchorage mechanics used in this study did not significantly enhance orthodontic anchorage despite retracting the upper anterior teeth in two stages. This goes in line with the concept that, in the treatment of premolar extraction patients 
with traditional mechanics, the maxillary molars were usually mesialized approximately $30 \%$ into the extraction space ${ }^{[79,80]}$.

Overall, there was a greater change in the soft tissue profile in mini-implant group than in conventional anchorage group with statistically significant results obtained for nasolabial and upper lip projection between the two anchorage groups. Nasolabial angle was increased and upper lip was retracted to a greater extent in mini-implant group than in conventional anchorage group. The amount of increase in nasolabial angle was $13.6^{\circ} \pm 8.08^{\circ}$ for group I and $6.6^{\circ} \pm 5.92^{\circ}$ for group II. While the amount of upper lip retraction relative to $\mathrm{Sv}$-line was $-5.3 \pm 1.49 \mathrm{~mm}$ for group I and $-3.2 \pm 2.09 \mathrm{~mm}$ for group II. Relative to E-line, it was $-3.7 \pm 1.77 \mathrm{~mm}$ for group I and $-1.8 \pm 2.2 \mathrm{~mm}$ for group II. These results were consistent with that of Upadhyay et al., $2008^{[26]}$, Kuroda et al., $2009^{[13]}$, Liu et al., 2009 ${ }^{[21]}$, Lee et al., 2014 ${ }^{[3]}$ and Sibaie and Hajeer, 2014 ${ }^{[27]}$ who found more retraction of the upper lip and consequently, increase in the nasolabial angle in the mini-implant group than in conventional anchorage group producing greater improvement in the facial profile.

Upadhyay and Yadav, $2007^{[34]}$ and Nagari et al., $2008^{[77]}$ reported significant retraction of the upper lip that resulted in decreased mentalis strain and improved chin projection. This difference was explained by Conley and Jernigan, $2006^{[81]}$,

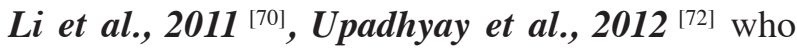
demonstrated that, the greater anchorage capacity of the mini-implants provides greater retraction of the upper incisors that gives more opportunity for the soft tissue between subnasale and labrale superius to move posteriorly.

En-masse retraction with mini-implants not only eases the biomechanics involved but also causes an early change in the facial profile. This together with the fact that spaces distal to the lateral incisors that are evident after individual canine retraction never appear with en-masse retraction, greatly enhances patient cooperation and motivation.

\section{CONCLUSION}

On the basis of the results obtained from the present study, the following treatment effects were concluded:

- The mini-implants placed in the interdental bone between the maxillary first molar and second premolar proved to be efficient for intraoral anchorage reinforcements for enmasse retraction and intrusion of the maxillary anterior teeth.

- There was no anchorage loss with miniimplants in either anteroposterior or vertical direction compared with conventional methods of anchorage reinforcement.

- Maxillary incisors were retracted more in the mini-implant than in conventional anchorage groups.

- A larger proportion of bodily retraction of maxillary incisors was observed in group I than in group II.

- Anticlockwise rotation of the mandible was recorded in G1 causing reduction in the anterior facial vertical dimension and increase in the posterior facial vertical dimension.

- The effect of two-step retraction aided with conventional anchorage mechanics was mainly dentoalveolar in nature.

- Greater improvement in the facial profile can be achieved by skeletal anchorage than with traditional anchorage mechanics.

- Greater retraction of the maxillary incisor, no anchorage loss of the maxillary first molars, and counterclockwise mandibular rotation all facilitated the correction of the class II malocclusion, especially for patients with a hyperdivergent face.

- No significant difference was found in the duration of retraction between the two studied groups. 


\section{REFERENCES}

1. Kuroda S, Fuji A, Sugie M, Uoi S, Kondo R, Ando $\mathrm{R}$, Yamashiro $\mathrm{T}$ : Relationship between orthodontic expertise and perception of treatment needs for maxillary protrusion: Comparison of dental students, residents, and orthodontists. Am J Orthod Dentofacial Orthop. 2010; 137:340-45.

2. Sharma JN: Skeletal and soft tissue point A and B changes following orthodontic treatment of Nepalese Class I bimaxillary protrusive patients. Angle Orthod. 2010; 80: 91-96.

3. Lee J, Miyazawa K, Tabuchi M, Sato T, Kawaguchi M, Goto S: Effectiveness of en-masse retraction using midpalatal miniscrews and a modified transpalatal arch: Treatment duration and dentoskeletal changes. Korean J Orthod. 2014; 44:88-95.

4. Melsen B, Bosch C. Different approaches to anchorage: a survey and an evaluation. Angle Orthod 1997; 67:23-30.

5. Yao CJ, Lai EH, Chang JZ, Chen I, Chen YJ: Comparison of treatment outcomes between skeletal anchorage and extraoral anchorage in adults with maxillary dentoalveolar protrusion. Am J Orthod Dentofacial Orthop. 2008; 134:615-24.

6. Upadhyay M, Yadav S, Patil S: Mini-implant anchorage for en-masse retraction of maxillary anterior teeth: A clinical cephalometric study. Am J Orthod Dentofacial Orthop. 2008; 134:803 -10.

7. Hart A, Taft L, Greenberg SN. The effectiveness of differential moments in establishing and maintaining anchorage. Am J Orthod Dentofacial Orthop 1992; 102:434-42.

8. Rajcich MM, Sadowsky C. Efficacy of intra-arch mechanics using differential moments for achieving anchorage control in extraction cases. Am J Orthod Dentofacial Orthop 1997; 112: 441-48.

9. Feldmann I, Bondemark L: Orthodontic anchorage: a systematic review. Angle Orthod. 2006; 76: 493-501.

10. Choi YJ, Chung CJ, Choy K, Kim KH: Absolute anchorage with universal T-loop mechanics for severe deepbite and maxillary anterior protrusion and its 10-year stability. Angle Orthod. 2010; 80:771-82.

11. Choi NC, Park YC, Lee HA, Kee-Joon Lee KJ: Treatment of class II protrusion with severe crowding using indirect miniscrew anchorage. Angle Orthod. 2007; 77: 1109-118.
12. Thiruvenkatachari B, Pavithranand A, Rajasigamani K, Kyung HM: Comparison and measurement of the amount of anchorage loss of the molars with and without the use of implant anchorage during canine retraction. Am J Orthod Dentofacial Orthop. 2006; 129: 551-54.

13. Kuroda S, Yamada K, Deguchi T, Kyung H, Yamamoto T: Class II malocclusion treated with miniscrew anchorage: Comparison with traditional orthodontic mechanics outcomes. Am J Orthod Dentofacial Orthop. 2009; 135: 302-9.

14. Kawakami M, Miyawaki S, Noguchi H, Kirita T: Screwtype implants used as anchorage for lingual orthodontic mechanics: A case of bimaxillary protrusion with second premolar extraction. Angle Orthod. 2004; 74: 715-19.

15. Shu R, Huang L, Bai D: Adult Class II Division 1 patient with severe gummy smile treated with temporary anchorage devices. Am J Orthod Dentofacial Orthop. 2011; 140: 97-105.

16. Paik CH, Ahn SJ, Nahm DS: Correction of Class II deep overbite and dental and skeletal asymmetry with 2 types of palatal miniscrews. Am J Orthod Dentofacial Orthop. 2007; 131: 106-16.

17. Papadopoulos MA, Tarawneh F: The use of miniscrew implants for temporary skeletal anchorage in orthodontics: A comprehensive review. Oral Surg Oral Med Oral Pathol Oral Radiol Endod. 2007; 103: e6-e15.

18. Park HS, Kim JY, Kwon TG: Treatment of a Class II deepbite with microimplant anchorage. Am J Orthod Dentofacial Orthop 2011; 139: 397-406.

19. Zablocki H, McNamara J, Franchi L, Baccetti T: Effect of the transpalatal arch during extraction treatment. Am J Orthod Dentofacial Orthop. 2008; 133:852-60.

20. Mclaughlin RP, Bennett JC. The transition from standard edgewise to preadjusted appliance systems. J Clin Orthod.1989; 23:142-53.

21. Liu YH, Ding WH, Liu J, Li Q: Comparison of the differences in cephalometric parameters after active orthodontic treatment applying mini-screw implants or transpalatal arches in adult patients with bialveolar dental protrusion. Journal of Oral Rehabilitation. 2009; 36: 687-95.

22. Park HS, Kwon TG: Sliding mechanics with microscrew implant anchorage. Angle Orthod. 2004; 74: 703-10.

23. Papadopoulos A: Orthodontic treatment of Class II malocclusion with miniscrew implants. Am J Orthod Dentofacial Orthop. 2008; 134: 604. e1-604.e16. 
24. Yao CC, Lee JJ, Chen HY, Chang ZC, Chang HF, Chen YJ: Maxillary molar intrusion with fixed appliances and miniimplant anchorage studied in three dimensions. Angle Orthod. 2005; 75: 754-60.

25. Carillo R, Buschang PH, Opperman LA, Franco PF, Rossouw EP: Segmental intrusion with mini-screw implant anchorage: a radiographic evaluation.Am J OrthodDentofacial Orthop.2007; 132: 576-76.

26. Upadhyay M, Yadav S, Nagaraj K, Patil S: Treatment effects of mini-implants for en-masse retraction of anterior teeth in bialveolar dental protrusion patients: A randomized controlled trial. Am J Orthod Dentofacial Orthop. 2008; 134: 18-29.

27. Al-Sibaie S, Hajeer MY: Randomized controlled trial. Assessment of changes following en-masse retraction with mini-implants anchorage compared to two-step retraction with conventional anchorage in patients with class II division 1 malocclusion: a randomized controlled trial. Eur J Orthod. 2014; 36: 275-83.

28. Park HS, Kwon OW, Sung JH: Microscrew implant anchorage sliding mechanics. World J Orthod. 2005; 6:265-74.

29. Kuroda S, Sugawara Y, Deguchi T, Kyung HM, TakanoYamamoto T: Clinical use of miniscrew implants as orthodontic anchorage: success rates and postoperative discomfort. Am J OrthodDentofacialOrthop. 2007; 131: 9-15.

30. Kaku M, Kojima S, Sumib H, Kosekib H, Abedinib S, Motokawaa M, Fujitaa T, Ohtania J, Kawatac T, Tanned $\mathrm{K}$ : Gummy smile and facial profile correction using miniscrew anchorage. Angle Orthod. 2012; 82: 170-77.

31. Choi NC, Park YC, Jo YM, Lee KJ: Combined use of miniscrews and clear appliances for the treatment of bialveolar protrusion without conventional brackets. Am J Orthod Dentofacial Orthop. 2009; 135: 671-81.

32. Ma J, Wang L, Zhang W, Chen W, Zhao C, Smales R: Comparative evaluation of micro-implant and headgear anchorage used with a pre-adjusted appliance system. Eur J Orthod. 2008; 30: 283-87.

33. Tseng YC, Hsieh CH, Chen CH, Shen YS, Huang IY, Chen CM: The application of mini-implants for orthodontic anchorage. Int J Oral Maxillofac Surg. 2006; 35: 704-7.

34. Upadhyay M, Yadav S: Mini-implants for retraction, intrusion and protraction in a class II division 1 patient. $\mathrm{J}$ Orthod. 2007; 34:158-67.
35. Baumgaertel S, Razavi MR, Hans MG: Mini-implant anchorage for the orthodontic practitioner. Am J OrthodDentofacialOrthop. 2008; 133:621- 27.

36. Schnelle MA, Beck FM, Jaynes RM, Huga SS: A radiologic evaluation of the availability of bone for placement of mini-screws. Angle Orthod. 2004; 74:832-37.

37. Park HS, Kwon TG, Sung JH: Nonextraction Treatment with Microscrew Implants. Angle Orthod. 2004; 74: 539-49.

38. Woodall N, Tadepalli SC, Qian F, Grosland NM, Marshall SD, Southard TE: Effect of miniscrew angulation on anchorage resistance. Am J Orthod Dentofacial Orthop. 2011; 139: 147-52

39. Laursen MG, Melsen B, Cattaneo PM: An evaluation of insertion sites for mini-implants. A micro-CT study of human autopsy material. Angle Orthod. 2013; 83: 222-29.

40. Araújo LH, Zenóbio EG, Pacheco W, Cosso MG, Manzi FR, Shibli JA: Mass retraction movement of the anterior upper teeth using orthodontic mini-implants as anchorage. Oral Maxillofac Surg. 2012; 16: 95-9.

41. Woods PW, Buschang PH, Owens SE, Rossouw PE, Opperman LA: The effect of force, timing, and location on bone-to-implant contact of miniscrew implants. Eur J Orthod. 2009; 31: 232-40.

42. Baty LD, Storie JD, Fraunhofer AJ: Synthetic elastromeric chains. A literature review. Am J Orthod Dentofacial Orthop. 1994; 105: 536-42.

43. Kyung HM, Park HS, Bae SM, Kwon OW, Sung JH: Development of orthodontic micro-implant (AbsoAnchor). Brochure for the AbsoAnchor orthodontic micriimplant. 2008; 6thed.

44. Tominaga J, Tanaka M, Koga Y, Gonzales C, Kobayashi M, Yoshida N: Optimal loading conditions for controlled movement of anterior teeth in sliding mechanics. A 3D finite element study. Angle Orthod. 2009; 79: 1102- 7.

45. Rinchuse DJ, Rinchuse DJ, Wadhwa RK. Orthodontic appliance design. Am J Orthod Dentofacial Orthop. 2007; 131: 76-82.

46. Basha AG, Shantaraj R, Mogegowda SB: Comparative study between conventional en-masse retraction (sliding mechanics) and en-masse retraction using orthodontic micro implant. Implant Dent. 2010; 19: 128-36.

47. Kravitz ND, Kusnoto B: Risks and complications of orthodontic mini screw. Am J Orthod. 2007; 131: S43-S51.

48. Garfinklea JS, Cunningham Jr, Beemanc CS, Kluemperd GT, Hickse EP, Kim MO: Evaluation of orthodontic 
mini-implant anchorage in premolar extraction therapy in adolescents. Am J OrthodDentofacialOrthop. 2008; 133: 642-53.

49. Upadhyay M, Yadav S, Nagaraj K, Nanda R: Dentoskeletal and soft tissue effects of mini-implants in class II division 1 patients. Angle Orthod. 2009; 79:240-47.

50. Kim SH, Hwang YS, Ferreira A, Chung KR: Analysis of temporary skeletal anchorage devices used for en-masse retraction: A preliminary study. Am J Orthod Dentofacial Orthop. 2009; 136: 268-76.

51. Chung KR, Nelson G, Kim SH, and Kook YA: Severe bidentoalveolar protrusion treated with orthodontic microimplant-dependent en-masse retraction. Am J Orthod Dentofacial Orthop. 2007; 132: 105-15.

52. Kim JS, Kim SH, Kook YA, Chung KR, Nelson G: Analysis of lingual en-masse retraction combining a C-lingual retractor and a palatal plate. Angle Orthod. 2011, 81: 662-69.

53. Erverdi N, Acar A: Zygomatic anchorage for en-masse retraction in the treatment of severe class II division 1. Angle Orthod. 2005; 75: 483-90.

54. Kokitsawat S, Manosudprasit M, Godfrey $\mathrm{K}$, Chatchaiwiwattana $\mathrm{C}$ : Clinical effects associated with miniscrews used as orthodontic anchorage. Aust Orthod J. 2008; 24:134-9.

55. Park HM, Kim BH, Yang HI, Baek SH: Preliminary three-dimensional analysis of tooth movement and arch dimension change of the maxillary dentition in Class II division 1 malocclusion treated with first premolar extraction: conventional anchorage vs mini-implant anchorage. Korean J Orthod. 2012; 42:280-90.

56. Benson PE, Tinsley D, O’Dwyer JJ: Midpalatal implants vs headgear for orthodontic anchorage-a randomized clinical trial: cephalometric results. Am J Orthod Dentofacial Orthop. 2007; 132:606-15.

57. Feldmann I, Bondemark L: Anchorage capacity of osseointegrated and conventional anchorage systems: a randomized controlled trial. Am J Orthod Dentofacial Orthop. 2008; 133: 339.e19-339.e28.

58. Huang X, Han P: Comparison of clinical effects between screw-implant and extra-force as anchorage. Beijing $\mathrm{J}$ Stomatol. 2007; 15: 213-15.

59. Lai EH, Yao CJ, Chang JZ, Chen I, Chen YJ: Threedimensional dental model analysis of treatment outcomes for protrusive maxillary dentition: Comparison of headgear, miniscrew, and miniplate skeletal anchorage. Am J Orthod Dentofacial Orthop. 2008; 134: 636-45.

60. Park HS, Yoon DY, Park CS, Jeoung SH: Treatment effects and anchorage potential of sliding mechanics with titanium screws compared with the Tweed-Merrifield technique. Am J Orthod Dentofacial Orthop. 2008; 133: 593-600.

61. Jee JH, Ahn HW, Seo KW, Kim SH, Kook YA, Chung KR, Nelson G: En-masse retraction with a preformed nickel-titanium and stainless steel archwire assembly and temporary skeletal anchorage devices without posterior bonding. Korean J Orthod. 2014; 44: 236-45.

62. Lee JS, Park HS, Kyung HM: Micro-Implant Anchorage for Lingual Treatment of a Skeletal Class II Malocclusion. J Clin Orthod. 2001; 10: 643-47.

63. Koyama I, Iino S, Abe Y, Yamamoto T, Miyawaki S: Differences between sliding mechanics with implant anchorage and straight-pull headgear and intermaxillary elastics in adults with bimaxillary protrusion. Eur J Orthod. 2011; 33: 126-31.

64. Lee J, Miyazawa K, Tabuchi M, Kawaguchi M, Shibata M, Goto S: Midpalatal miniscrews and high-pull headgear for anteroposterior and vertical anchorage control: Cephalometric comparisons of treatment changes. Am J Orthod Dentofacial Orthop 2013; 144: 238-50.

65. Kuhn RJ: Control of anterior vertical dimension and proper selection of extraoral anchorage. Angle Orthod. 1968; 38:340-9.

66. Upadhyay M, Yadav S, Nanda R: Vertical-dimension control during en-masse retraction with mini-implant anchorage. Am J Orthod Dentofacial Orthop. 2010; 138: 96-108.

67. Staggers JA. A comparison of results of second molar and first premolar extraction treatment. Am J Orthod Dentofacial Orthop. 1990; 98: 430-6.

68. Cusimano C, McLaughlin RP, Zernik JH: Effects of first bicuspid extractions on facial height in high-angle cases. $\mathrm{J}$ Clin Orthod 1993; 27:594-8.

69. Qin M, Mao J: Micro implant versus extraoral J hook for Angle Class II division 1 malocclusion. J Clin Rehabil Tissue Eng Res. 2008; 12:8705-8.

70. Li F, Hu HK, Chen JW, Liu ZP, Li GF, He SS, Zou SJ, Ye QS: Comparison of anchorage capacity between implant and headgear during anterior segment retraction.A Systematic Review. Angle Orthod. 2011; 81:915-22. 
71. Chetan.S, Keluskar KM, Vasisht VN, Revankar S: Enmasse retraction of the maxillary anterior teeth by applying force from four different levels - A Finite Element Study. Journal of Clinical and Diagnostic Research. 2014; 9:26-30.

72. Upadhyay M, Yadav S, Nagaraj K, Uribe F, Nanda R: Mini-implants vs fixed functional appliances for treatment of young adult Class II female patients. A prospective clinical trial. Angle Orthod. 2012; 82: 294-303.

73. Jung MH, Kim TW: Biomechanical considerations in treatment with miniscrew anchorage. Part I: the sagittal plane. J Clin Orthod. 2008; 42: 79-83.

74. Teuscher U: A growth-related concept for skeletal Class II treatment. Am J Orthod. 1978; 74: 258-75.

75. Aljhani A, Zawawi KH: The use of mini-implants in en-masse retraction for the treatment of bimaxillary dentoalveolar protrusion. Saudi Dental Journal. 2010; 22: 35-39.

76. Park YC, Choi YJ, Choi NC, Lee JS: Esthetic segmental retraction of maxillary anterior teeth with a palatal appliance and orthodontic mini-implants. Am J Orthod Dentofacial Orthop. 2007; 131: 537-44.

77. Nagaraj K, Upadhyay M, Yadav S: Mini-implant anchorage for a skeletal class II malocclusion with missing mandibular incisors: A case report. World J Orthod. 2008; 9:155-66

78. Wilmes B, Olthoff G, Drescher D: Comparison of skeletal and conventional anchorage methods in conjunction with pre-operative decompensation of a skeletal class III malocclusion. J Orofac. Orthop. 2009; 70:297-305.

79. Kocadereli I: The effect of first premolar extraction on vertical dimension. Am J Orthod Dentofacial Orthop 1999; $116: 41-5$

80. Kim TK, Kim JT, Mah J, Yang WS, Baek SH: First or second premolar extraction effects on facial vertical dimension. Angle Orthod 2005; 75:177-82.

81. Conley RS, Jernigan C. Soft Tissue Changes after Upper Premolar Extraction in Class II Camouflage Therapy. Angle Orthod. 2006; 76:59-65. 